\title{
Unresectable Colorectal Liver Metastases: Percutaneous Ablation Using CT-Guided High-Dose-Rate Brachytherapy (CT-HDBRT)
}

\section{Nicht resektable kolorektale Lebermetastasen: perkutane Ablation mittels CT-gesteuerter Hochdosisbrachytherapie (CT-HDBRT)}

Authors

Affiliations
F. Collettini ${ }^{1}$, A. Lutter ${ }^{1}$, D. Schnapauff ${ }^{1}$, B. Hildebrandt ${ }^{2}$, G. Puhl ${ }^{3}$, T. Denecke ${ }^{1}$, P. Wust ${ }^{4}$, B. Gebauer ${ }^{1}$

Affiliation addresses are listed at the end of the article.

\section{Key words \\ - abdomen \\ - ablation procedures \\ - interventional procedures \\ - metastases \\ - radiofrequency (RF) ablation}

received $\quad 4.1 .2013$

accepted 15.9.2013

Bibliography

Dol http://dx.doi.org/

10.1055/s-0033-1355887

Published online: 2014

Fortschr Röntgenstr 2014; 186:

606-612 @ Georg Thieme

Verlag KG Stuttgart · New York . ISSN 1438-9029

\section{Correspondence Dr. Federico Collettini \\ Radiologie, Charité - Universitätsmedizin Berlin Augustenburger Platz 1 13353 Berlin Germany \\ Tel.: ++ 49/304/50557001 Fax: ++ 49/304/50557901 federico.collettini@charite.de}

\section{Abstract}

Purpose: To evaluate the clinical outcome of CT-guided high-dose-rate brachytherapy (CTHDRBT) of unresectable colorectal liver metastases (CRLMs).

Materials and Methods: Retrospective analysis of all consecutive patients with unresectable CRLMs treated with CT-HDRBT between January 2008 and November 2012. Treatment was performed by CT-guided catheter placement and high-dose-rate brachytherapy with an iridium-192 source. MRI follow-up was performed after 6 weeks and then every 3 months post-intervention. The primary endpoint was local tumor control (LTC); secondary endpoints included time to progression (TTP) and overall survival (OS).

Results: 80 heavily pretreated patients with 179 metastases were available for MRI evaluation for a mean follow-up time of 16.9 months. The mean tumor diameter was $28.5 \mathrm{~mm}$ (range: $8-107 \mathrm{~mm}$ ). No major complications were observed. A total of 23 (12.9\%) local tumor progressions were observed. Lesions $\geq 4 \mathrm{~cm}$ in diameter showed significantly more local progression than smaller lesions $(<4 \mathrm{~cm}) .50$ patients $(62.5 \%)$ experienced systemic tumor progression. The median TTP was 6 months. 28 (43\%) patients died during the follow-up period. The median OS after ablation was 18 months.

Conclusion: CT-HDRBT is an effective technique for the treatment of unresectable CRLMs and warrants promising LTC rates compared to thermal ablative techniques. A combination with other local and systemic therapies should be evaluated in patients with lesions $>4 \mathrm{~cm}$ in diameter, in which higher progression rates are expected.
Key Points:

- CT-HDRBT enables a highly cytotoxic irradiation of colorectal liver metastases with simultaneous conservation of important neighboring structures (eg liver parenchyma, bile ducts and bowel)

- The local tumor control rates obtained by CT-HDRBT in patients with colorectal liver metastases are promising, also compared to the local tumor control rates after RFA

- Metastases with a diameter of $4 \mathrm{~cm}$ or abow, display a higher local progression rate after CT-HDRBT, therefor a combination therapy with other locoregional or systemic treatments should be investigated in prospective studies

Citation Format:

- Collettini F, Lutter A, Schnapauff D et al. Unresectable Colorectal Liver Metastases: Percutaneous Ablation Using CT-Guided HighDose-Rate Brachytherapy (CT-HDBRT). Fortschr Röntgenstr 2014; 186: 606-612

\section{Zusammenfassung}

$\nabla$

Ziel: Evaluierung der Behandlungsergebnisse der CT-gesteuerten Hochdosisbrachytherapie (CT-HDRBT) bei irresektablen kolorektalen Lebermetastasen (CRLM).

Material und Methoden: Retrospektive Analyse von allen konsekutiven Patienten mit irresektablen CRLM, die zwischen Januar 2008 und November 2012 mittels CT-HDRBT behandelt wurden. Die Behandlung erfolgte über eine CT-gesteuerte Hochdosisbrachytherapie mittels einer Iridium-192Quelle. Post interventionelle Kontrollen erfolgten durch kontrastverstärkte MRT-Untersuchungen nach 6 Wochen nach Ablation und anschließend alle 3 Monate. Als primärer Endpunkt wurde die lokale Tumorkontrolle festgelegt. Als sekundäre Endpunkte wurden das progressionsfreie Intervall 
und das Gesamtüberleben nach Ablation untersucht.

Ergebnisse: 80 zumeist intensiv vorbehandelte Patienten mit 179 irresektablen Lebermetastasen konnten eingeschlossen werden. Die mittlere Verlaufskontrollzeit betrug 16,9 Monate. Der mittlere Durchmesser der Metastasen betrug 28,5 mm (8$107 \mathrm{~mm}$ ). Es traten keinerlei Komplikationen auf. 23 Metastasen $(12,8 \%)$ entwickelten eine lokale Progression. Metastasen $\geq 4 \mathrm{~cm}$ im Diameter zeigten eine signifikant höhere lokale Progressionsrate als kleinere Metastasen $(<4 \mathrm{~cm})$. Bei 50 Patienten $(62,5 \%)$ zeigte sich im Verlauf ein Voranschreiten der Tumorerkrankung in Form eines nicht lokalen intrahepatischen oder extrahepatischen Tumorprogress. Das mediane progressionsfreie Überleben lag bei 6 Monaten. 28 Patienten (43\%) starben während des Follow-ups. Das mediane Gesamtüberleben nach Ablation betrug 18 Monate.

Schlussfolgerungen: Die CT-HDRBT ist eine aussichtsreiche Technik zur Ablation von CRLM mit der man, im Vergleich zu den thermischen Ablationsverfahren, sehr vielversprechende lokale Tumorkontrollraten erzielen kann. Bei Läsionen mit einem Durchmesser $>4 \mathrm{~cm}$, bei denen höhere Progressionsrate zu erwarten sind, sollte eine Kombination mit anderen lokalen oder systemischen Therapien erwogen werden. Dies gilt es in weiteren klinischen Studien zu untersuchen.

\section{Introduction}

$\nabla$

In Western industrialized countries, colorectal carcinoma is one of the most common types of malignant tumor and a leading cause of death $[1,2]$. Synchronous or metachronous liver metastases are diagnosed in approximately half of all patients with advanced colorectal carcinoma in the course of the disease [3]. In the event that the metastases are resectable, hepatic resection with a 5-year survival rate of approx. $40 \%$ offers the greatest chance of recovery [4]. However, primary surgical resection of liver metastases is only possible in approximately one-fourth of cases [4]. Considerable advances in the treatment of primarily unresectable colorectal liver metastases (CRLMs) have been made in recent years. Treatment with new systemic therapies including biological agents like cetuximab and bevacizumab results in better response rates so that up to $28 \%$ of patients with primarily unresectable CRLMs can undergo subsequent liver resection [5]. However, resection is not possible in the majority of patients despite neoadjuvant chemotherapy and new liver metastases occur after liver resection in $70 \%$ of cases [6].

This resulted in the development of different alternative tumor ablation procedures for unresectable and recidivating liver metastases [7]. Thermal ablation procedures, such as radiofrequency ablation (RFA) and laser-induced thermotherapy (LITT), are the most widely used and most studied methods. Numerous retrospective and prospective studies have been able to show promising results with thermal ablation procedures in selected patients over the last ten years so that these procedures are currently considered a valid treatment option for patients with inoperable liver metastases [8-16]. In the recently published CLOCC study, Ruers and colleagues were able to show that a combination of RFA and systemic therapy is superior to systemic therapy alone with respect to the goal of progression-free survival (16.8 vs. 9.9 months) [17].
However, these studies have also shown several important limitations that restrict the use of thermal ablation procedures. This includes tumor size, a critical intrahepatic position, and proximity to risk structures (e.g. stomach, colon, and bile ducts) [18].

Transarterial procedures such as chemoembolization (TACE) and $\mathrm{Y}-90$ radioembolization (RE) and radiation therapy procedures such as stereotactic radiation therapy (SBRT) are always used more frequently as valid therapeutic alternatives for unresectable and non-ablatable CRLMs.

An alternative one-time radioablative method is CT-guided high-dose-rate brachytherapy (CT-HDRBT) in which an iridium-192 source is temporarily introduced into the target lesion via a catheter under imaging guidance [19].

Initial clinical studies have shown that CT-HDRBT allows effective local ablation of primary and secondary liver tumors as well as extrahepatic abdominal tumors. Very promising local tumor control rates were seen and it was shown that these are principally not dependent on tumor location, vascularization, and size in contrast to thermal ablation procedures [20, 21].

In this retrospective article, we report our results in a cohort of 80 patients with 179 unresectable colorectal liver metastases and discuss them in comparison with published results achieved with thermal methods.

\section{Materials and Methods}

\section{$\nabla$}

All consecutive patients with inoperable colorectal liver metastases treated at our clinic via CT-guided high-doserate brachytherapy (CT-HDRBT) between January 2008 and November 2012 were included in this retrospective analysis. A positive vote of the ethics committee for retrospective analysis of the patient data was obtained. The indication for CT-HDRBT was determined for all patients in an interdisciplinary consensus of visceral surgeons, medical oncologists, gastroenterologists, radiotherapists, and interventional radiologists. Surgical resection of the primary tumor was performed in all patients prior to ablation. The inclusion criteria for performing CT-HDRBT were: (1) Technically unresectable lesions (e.g. reduced liver function or low residual liver tissue) (2) medical contraindication for resection or comorbidities and (3) refusal of operation. The following were contraindications (1) more than 5 liver metastases (2) presence of prognosis-limiting, extrahepatic metastases (i. e., a non-liver-dominant disease), (3) uncorrectable coagulation defects (target values: thrombocytes $>50000 / \mathrm{nl}$, quick $>50 \%$, partial thromboplastin time $<50$ seconds) and (4) lack of patient consent. There were no limitations with respect to the size and location of the lesions.

The afterloading catheter was placed under CT fluoroscopy (Somatom Definition AS, Siemens, Erlangen, Germany). All interventions were performed under i.v. analog sedation with an initial dose of $50 \mu \mathrm{g}$ fentanyl and $1 \mathrm{mg}$ midazolam. The doses were adjusted on an individual basis as needed. Local anesthesia of the puncture site was performed with approx. $10-20 \mathrm{ml}$ of lidocaine (Xylonest $1 \%$ ). After puncture of the liver metastasis with a 17-G needle, a 6-F angiography introducer sheath (Radiofocus Introducer II FR 6, Terumo $^{\text {TM }}$, Tokyo, Japan) was inserted via a stiff angiographic guide wire (Amplatz $145 \mathrm{~cm}, 0,35$ ", Boston Scientific, Bos- 

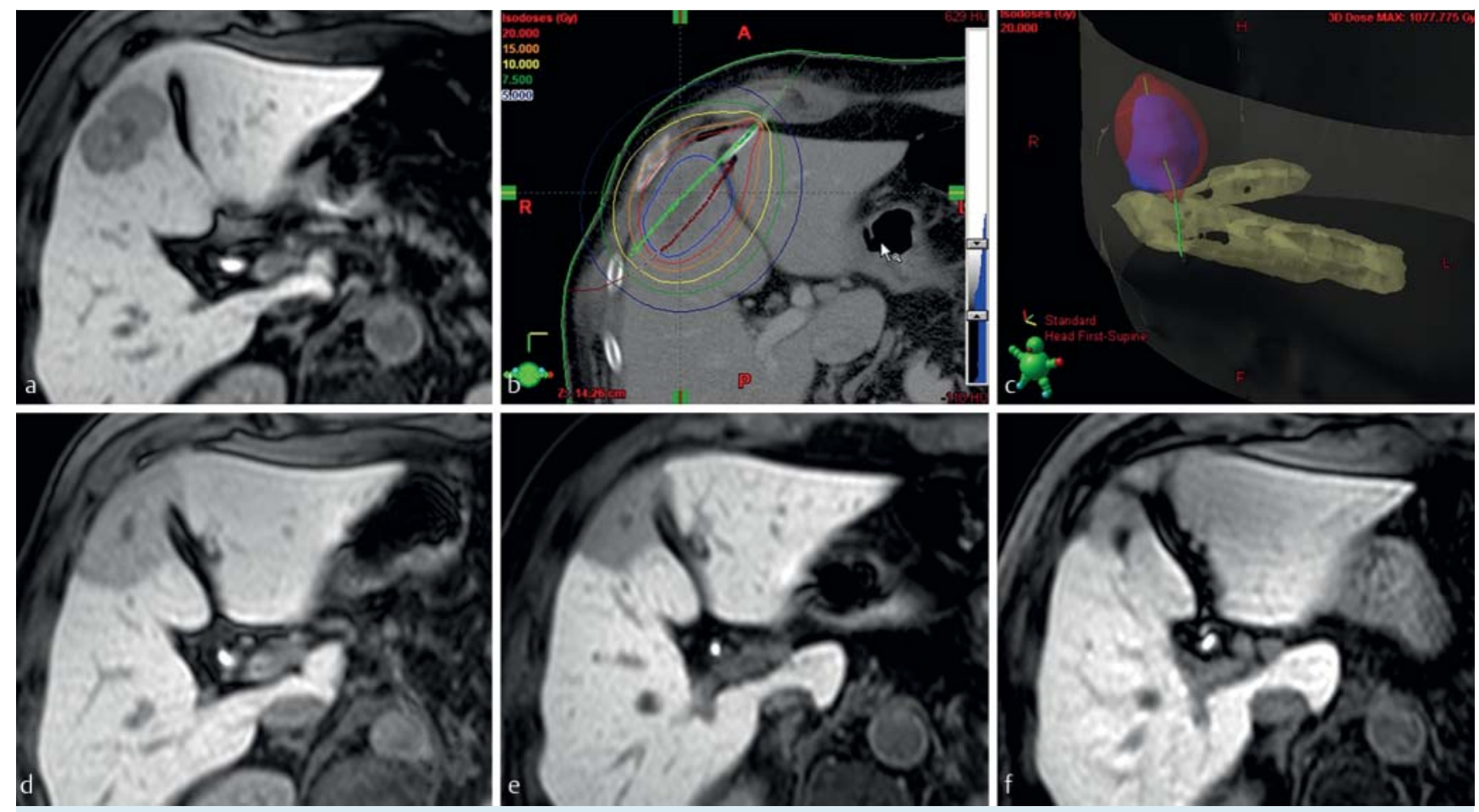

Fig. 1 86-year-old man with a 4.3-cm metachronous liver metastasis of a carcinoma of the sigmoid colon a. Radiation therapy planning for CT-HDRBT with the risk structures drawn in (yellow = intestines) $\mathbf{b}, \mathbf{c}$. A reduction in the size of the metastasis was seen after $3 \mathbf{d}, 6 \mathbf{e}$, and $12 \mathbf{f}$ months.

ton, MA, USA) using the Seldinger technique. The guide wire was then removed and a 350-mm 6-F afterloading catheter with a closed end (Primed ${ }^{\mathrm{TM}}$, Halberstadt Medizintechnik GmbH Halberstadt, Germany) was then inserted into the introducer sheath. The inserted catheter was secured via skin sutures and covered with sterile bandages. After the positioning of the afterloading catheter, a contrast-enhanced spiral CT scan of the liver was acquired using the breathhold technique for the purpose of radiation therapy planning.

Computer-aided $3 \mathrm{D}$ radiation therapy planning was performed using the acquired dataset and the Brachyvision ${ }^{\mathrm{TM}}$ software (Gammamed ${ }^{\mathrm{TM}}$, Varian, Palo Alto, CA, USA). For this purpose, all afterloading catheters were drawn from the tip to the body exit point. The liver metastases were then drawn as a clinical target volume (CTV) and all relevant risk structures (e.g. stomach, esophagus, duodenum, and spinal canal) were marked ( $\bullet$ Fig. 1 ). In the case of large-volume metastases, the liver volume and possibly the kidneys were additionally drawn in to prevent a post-radiogenic loss of function. The retention times of the iridium192 solid source in the catheter were optimized semiautomatically and manually to ensure complete coverage of the target volume while protecting the risk structures. The minimum dose for covering the clinical target volume was 20 Gy [20]. Maximum doses > 50 Gy were permitted in the tumor center. All radiation therapy was administered as single-fraction irradiation via an afterloading system (Gammamed $^{\mathrm{TM}}$, Varian, Palo Alto, CA, USA). Iridium-192 (192Ir) with a nominal activity of $10 \mathrm{Ci}$ and a diameter of $<1 \mathrm{~mm}$ was used as the radiation source. The radiation therapy procedure typically lasted between 20 and 40 minutes. Once the introducer sheaths were removed, the puncture channels were closed with thrombogenic material (gelatin or fibrin) and the patients were transferred back to the ward.

Follow-up after CT-HDRBT was performed via Gd-EOBDTPA-enhanced MRI after six weeks and then at intervals of three months. The MRI follow-up scans were analyzed by two observers in consensus.

The technical success of the treatment was evaluated by comparing the initial MRI to the first follow-up MRI. In the case of successful treatment, a hypointense border around the lesion was seen on the contrast-enhanced T1-weighted sequence. This corresponds to the post-radiogenic loss of the ability of the hepatocytes to absorb liver-specific contrast agent and is achieved starting at a radiation dose of 10 Gy [22]. An increase in the size of the treated metastases and every new nodular growth in the ablation area were evaluated as local tumor progression (LTP). The new occurrence of intrahepatic or extrahepatic metastases and an increase in the size of untreated metastases were evaluated as systemic tumor progression (STP).

Severe complications of CT-HDRBT were classified according to the standards of the "Society of Interventional Radiology" [23].

The acquired data were saved in Microsoft Excel and imported to IBM SPSS (Superior Performance Software System, version 19.0) for statistical analysis The local tumor control rate, the progression-free survival time, and the probability of survival were calculated using Kaplan-Meier analyses. The Chi-square test was used as the statistical test method for testing the significance of the results. p-values $<0.05$ were considered statistically significant. 
Table 1 Characteristics of the patient population and the tumors (percentage in parentheses).

\begin{tabular}{|c|c|}
\hline \multicolumn{2}{|l|}{ parameter } \\
\hline $\operatorname{sex}(m: f)$ & $60: 20$ \\
\hline age (years) (MV $\pm S D)$ & $65.7 \pm 10.4$ \\
\hline \multicolumn{2}{|l|}{ location of primary tumor } \\
\hline - colon & $19(23.8 \%)$ \\
\hline - sigma & $19(23.8 \%)$ \\
\hline - rectum & $39(48.8 \%)$ \\
\hline - unknown & $3(3.8 \%)$ \\
\hline patient/lesions & $80 / 179$ \\
\hline synchronous metastasization & $50(62.5 \%)$ \\
\hline metachronous metastasization & $30(37.5 \%)$ \\
\hline previous liver resection & $41(51.2 \%)$ \\
\hline lesion diameter (mm) (range) & $28.5(8-107)$ \\
\hline$-<40 \mathrm{~mm}$ & $76 \%$ \\
\hline$-\geq 40 \mathrm{~mm}$ & $24 \%$ \\
\hline
\end{tabular}

\section{Results}

$\nabla$

Within the 47-month period, a total of 179 colorectal liver metastases in 80 patients were treated via CT-HDRBT. The demographic data of the patients are summarized in - Table 1.

The 179 metastases were ablated in a total of 142 treatment sessions. $37(46.25 \%)$ of the patients underwent a single treatment, 29 (36.25\%) of the patients underwent 2 interventions, 11 (13.75\%) of the patients received 3 treatments, $2(2.5 \%)$ of the patients underwent 4 ablations and only 1 ( $1.25 \%)$ of the patients underwent 6 ablations.

In total, 336 afterloading catheters were used. This corresponds to an average of 2.4 afterloading catheters per ablation. The number of afterloading catheters used depended on the size, position, and conformation of the tumor, the maximum number of catheters used being 5 . The average tumor-enclosing radiation dose was $19.1 \mathrm{~Gy}$ (range: $15-$ $20 \mathrm{~Gy})$. On average, the CTV was $43.9 \mathrm{ml}(0.8-319 \mathrm{ml})$. The average coverage was $94.9 \%$ (51-100\%). Major complications did not occur in any of the treated patients in the first 90 days after ablation.

41 (51.2\%) of the 80 patients had already undergone a previous liver resection at the time of CT-HDRBT. No patients received simultaneous chemotherapy at the time of CTHDRBT.

The median follow-up time was 16.9 months. During this time, local tumor progression (LTP) was observed in 23 of the 179 treated liver metastases (12.9\%). The local tumor control rate after 12,24 , and 36 months was $88.3 \%, 81.2 \%$, and $68.4 \%$, respectively. The median local tumor control time was 10.7 months ( $\bullet$ Fig. 2). After 12 and 24 months, the local tumor control rate was $94 \%$ and $86.8 \%$, respectively, for metastases with a diameter of $<4 \mathrm{~cm}$ and $65.8 \%$ and $58.5 \%$, respectively, for metastases $\geq 4 \mathrm{~cm} \quad(p=0.00421)$ (॰ Fig. 3).

The local progression was treated with another CT-HDRBT procedure in 12 patients ( $52 \%$ ) and 2 patients (8.7\%) underwent Y-90 radioembolization as salvage therapy. The local progression was accompanied by simultaneous systemic progression in the form of disseminated intrahepatic or extrahepatic progression in 9 patients (39\%) so that locoregio-

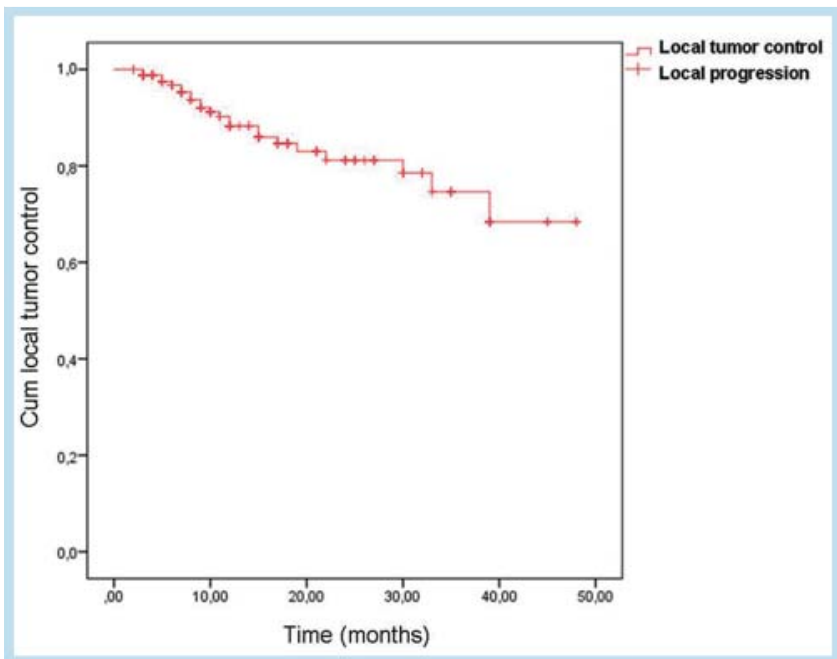

Fig. 2 Local tumor control rate with CT-HDRBT. The local tumor control rate after 12,24 , and 36 months was $88.3 \%, 81.2 \%$, and $68.4 \%$, respectively.

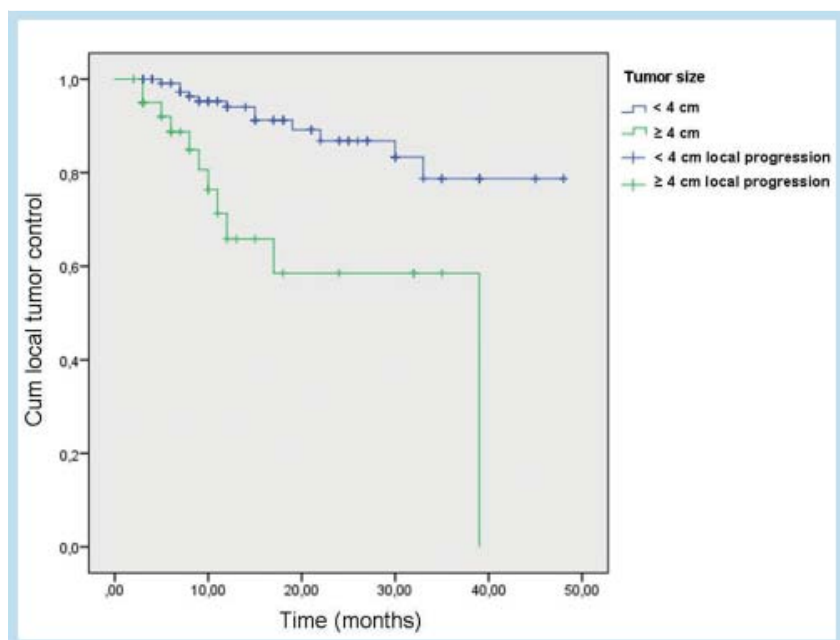

Fig. 3 Local tumor control rate as a function of tumor size. The local tumor control rate after 12 and 24 months was $94 \%$ and $86.8 \%$, respectively, for metastases $<4 \mathrm{~cm}$ and $65.8 \%$ and $58.5 \%$, respectively, for metastases $\geq 4 \mathrm{~cm}$.

nal therapy no longer seemed productive. These patients were treated with systemic chemotherapy.

50 of the 80 (62.5\%) patients showed systemic tumor progression (STP) in the sense of non-local intrahepatic or extrahepatic tumor progression during the follow-up period. The median progression-free survival time was 5 months (० Fig. 4).

At the time of the analysis 15 patients had been lost in the follow-up period (average follow-up time: 16.4 months) and could therefore not be included in the survival analysis. $28(43 \%)$ of the treated patients died as a result of their colorectal carcinoma.

The total survival rate after 12, 24, and 36 months was $87.6 \%, 57.3 \%$, and $41.6 \%$, respectively. The median survival time after CT-HDRBT was 18 months (๑ Fig.5). 


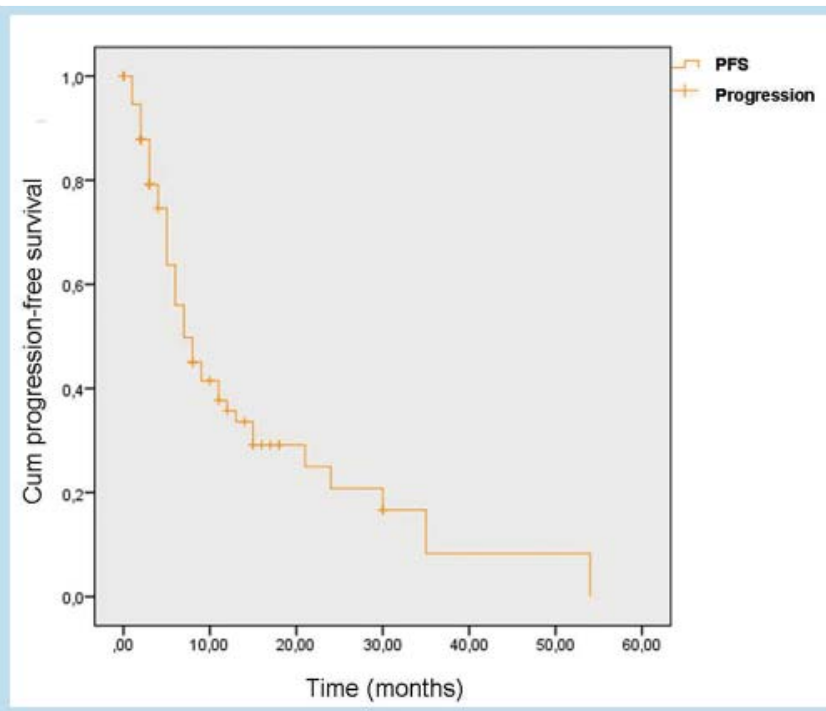

Fig. 4 Progression-free survival after CT-HDRBT. 50 of the 80 (62.5\%) patients showed systemic tumor progression during the follow-up period. The median progression-free survival time was 6 months.

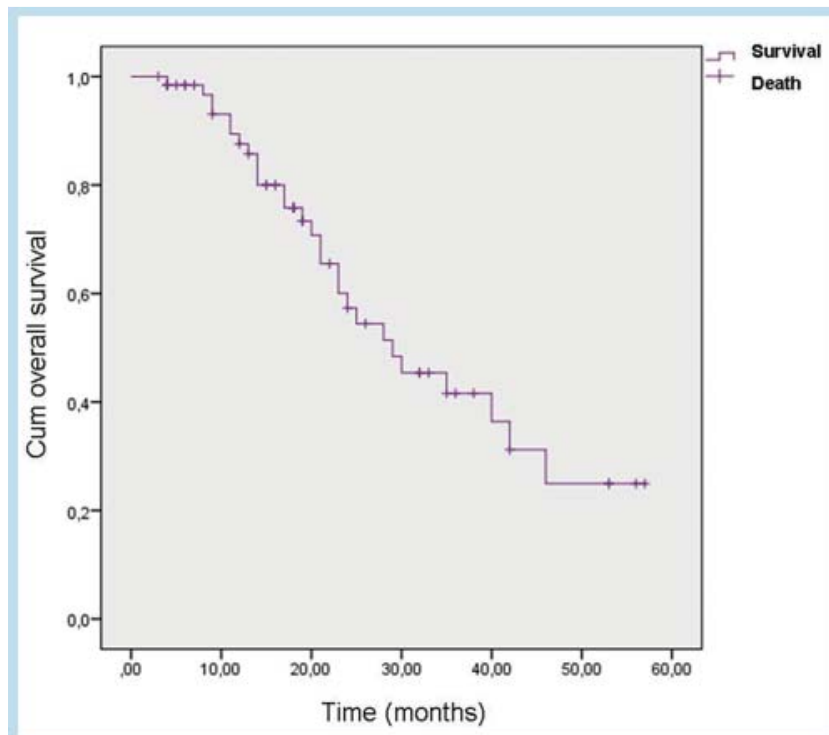

Fig. 5 Total survival rate after CT-HDRBT. The total survival rate after 12 , 24 , and 36 months was $87.6 \%, 57.3 \%$, and $41.6 \%$, respectively. The median survival time after CT-HDRBT was 18 months.

Table 2 Overview of the results of the percutaneous radiofrequency ablation of colorectal liver metastases.

\begin{tabular}{|c|c|c|c|c|c|c|}
\hline author (year) & patients (tumors) & $\begin{array}{l}\text { tumor diameter } \\
\text { (cm) [range] }\end{array}$ & $\begin{array}{l}\text { follow-up (months) } \\
\text { [range] }\end{array}$ & local progression & $\begin{array}{l}\text { systemic } \\
\text { progression }\end{array}$ & $\begin{array}{l}\text { median survival } \\
\text { time (months) }\end{array}$ \\
\hline Solbiati et al. (2001) & $117(179)$ & $2.8[0.7-9.6]$ & $18[6-52]$ & $39.1 \%$ & $66 \%$ & 36 \\
\hline Livraghi et al. (2003) & $80(134)$ & $N A[N A-4]$ & 28 [NA] & $40 \%$ & $70 \%$ & NA \\
\hline Gilliams et al. (2004) & 167 (NA) & $3.9[1-12]$ & NA [NA] & NA & NA & 32 \\
\hline Jakobs et al. (2006) & $68(183)$ & $22.8[0.5-5]$ & $21.4[6-38]$ & $18 \%$ & NA & NA \\
\hline Sørensen et al. (2007) & $102(332)$ & $2.2[0.5-6.5]$ & $23.6[1-92]$ & NA & NA & 32 \\
\hline Veltri et al. (2008) & $122(199)$ & $2.9[0.5-8]$ & $19[1-86]$ & $26 \%$ & $74 \%$ & 31.5 \\
\hline Gillams et al. (2008) & $40(40)$ & $2.3[0.8-4]$ & $38[6-132]$ & $42 \%$ & $68 \%$ & 59 \\
\hline Veltri et al. (2012) & $240(248)$ & $2.7[\mathrm{NA}]$ & $26.4[2.4-129.6]$ & NA & NA & 32 \\
\hline Solbiati et al. (2012) & $99(202)$ & $2.2[0.8-4]$ & $53[36-136]$ & $11.9 \%$ & NA & 53.2 \\
\hline
\end{tabular}

\section{Discussion}

Liver metastases continue to represent a special therapeutic challenge in patients with colorectal carcinoma. In the majority of cases, primary resection of liver metastases is not possible or new liver metastases arise in the postoperative period [2]. For this reason different minimally invasive ablation procedures have been developed and tested in the last 20 years. Thermal procedures such as radiofrequency ablation (RFA), which is currently the most widely used method, are the most investigated ablation methods.

Numerous studies regarding percutaneous ablation of liver metastases of colorectal carcinoma via RFA are available. The results of the most important studies are summarized in 0 Table 2. Very different RFA success rates in colorectal liver metastases have been reported, the treatment success seeming to depend on different factors such as the number of metastases, the lesion size, and the intrahepatic location [18].

It is largely agreed that the local tumor control rate after RFA is low for a metastasis diameter of greater than $4 \mathrm{~cm}$ [8]. Micro-satellite metastases in the vicinity of the metas- tases visible on $\mathrm{CT} / \mathrm{MRI}$ are presumably responsible for this. Solbiati et al. were able to show a significant relationship between local recidivation and metastasis size at the time of treatment in one of the first clinical studies regarding RFA of colorectal liver metastases [8].

These results were confirmed in further studies including a recent study in which tumor size was shown to be the most important prognostic factor for the success of the treatment of liver metastases via RFA [15].

A critical intrahepatic tumor location also has a negative effect on the success of thermal ablation. Perfusion-related cooling (the so-called "heat-sink effect") can cause incomplete ablation particularly in the vicinity of large vessels. Therefore, in a study published in 2002, Lu et al. showed a border of vital tissue around $100 \%$ of all vessels $>5 \mathrm{~mm}$, around $29 \%$ of vessels with a diameter of $3-5 \mathrm{~mm}$, and around $3 \%$ of vessels $>3 \mathrm{~mm}$ after RFA [24]. Multiple clinical studies have shown an increased failure rate for RFA of liver tumors in the proximity of large blood vessels in the following years.

Incomplete ablation jeopardizes the treatment success. Newer studies have shown that incomplete thermal abla- 
tion results in a significant increase in cell proliferation and resistance to apoptosis [25].

In light of these limitations of thermal ablation procedures, the focus of research in the area of interventional oncology recently turned to the development of alternative ablation procedures (like irreversible electroporation [IRE]). However, this method has only been minimally studied with respect to the local control rate and patient survival.

Yttrium-90 radioembolization (RE) is an alternative treatment option for patients with CRLMs for whom all other systemic and local therapies (chemotherapy, surgery, local ablative procedures) have been exhausted. In one of the largest studies regarding RE in CRLMs, Kennedy et al. achieved a promising median survival time (10.5 months) with acceptable toxicity (24\% degree 2 and $4 \%$ degree 3 ) and a significant objective response rate $(P R=35 \%, 55 \%$ $=\mathrm{SD})$ in a group of 208 highly pretreated patients [26]. These results were also confirmed a few years later by a European group: Jakobs et al. reported a median survival time of 10.5 months in 41 patients with chemo-resistant CRLMs treated with RE [27].

In the past, radiation therapy had a secondary role in the treatment of liver tumors due to the relatively high liver toxicity. Stereotactic radiation therapy (SBRT) allows precise hypofractionated dose application with high local tumor control rates and low toxicity. In a study published in 2010, van der Pool et al. were able to show that SBRT represents a valid and safe therapeutic alternative for the treatment of unresectable and non-ablatable liver metastases [28]. In a more recent study, Bae and colleagues treated 41 patients with 50 liver metastases with high-dose SBRT (dose $\geq 45 \mathrm{~Gy}$ ). The 5 -year local tumor control rate was $57 \%$. The median survival time was 28 months and the 5 -year survival rate was $38 \%$ [29].

CT-HDRBT is a radioablative technique with which circumscribed, highly cytotoxic high-dose radiation therapy can be applied in the clinical target volume. The dose drops rapidly outside the target volume so that surrounding tissue such as normal liver parenchyma and bile ducts as well as the duodenum, segments of the intestine and other extrahepatic structures can be protected. Moreover, the effectiveness of the treatment is not affected by heat dissipation into adjacent vessels ("heat-sink effect") [19].

Our results in a relatively large cohort of patients already treated multiple times show that CT-HDRBT is a safe and reliable minimally invasive ablation procedure. Although the majority $(51.2 \%)$ of patients were already treated surgically (e.g. liver resection), no major complications occurred.

The local tumor control rate is an important parameter for the evaluation of an ablation procedure. The local tumor progression rates after RFA cited in the literature are very different and range from $11.9-40 \%$.

The local tumor progression rate in our series at an average follow-up time of 16.9 months was $12.9 \%$. Therefore, our results are very promising with respect to the local tumor control rate compared to local tumor control rates after RFA, in particular when it is taken into consideration that we treated significantly larger metastases than are usually treated with RFA.

The local tumor control rates for SBRT fluctuate greatly in the literature: van der Pool et al. report a local tumor control rate of $31 \%$ after an average follow-up period of 26 months [28]. Excellent local tumor control rates have been reported in more recent studies: Scorsetti et al. report a local tumor control rate of $94 \%$ after an average follow-up period of 12 months [30]. Therefore, SBRT appears to be a valid and effective alternative for the treatment of unresectable liver metastases. In our view a continuing limitation of SBRT is the morbidity associated with SBRT that still seems relatively high in recent studies ( $6 \%$ severe complications in the case of CRLMs) [31].

If we compare the results of CT-HDRBT in colorectal liver metastases with those of other types of tumors, the achieved results seem less satisfactory. Therefore, a local tumor control rate of $93.3-96.1 \%$ could be achieved via CTHDRBT in hepatocellular carcinoma and a rate of $96.5-$ $97.4 \%$ in breast carcinoma metastasized to the liver [21, $32-34]$.

A study by Ricke et al. also showed a lower local tumor control rate of CT-HDRBT for liver metastases of colorectal carcinoma compared to other types of tumors [20]. In our opinion, this is due to the lower radiosensitivity of colorectal carcinoma compared to other carcinomas.

In contrast to earlier studies that found satisfactory local tumor control rates even in very large lesions, significant worsening of the local tumor control rate at tumor sizes of greater than $4 \mathrm{~cm}(\mathrm{p}=0.00421)$ was seen in our cohort.

There is the option here to combine ablation with other local or systemic therapies to treat tumors with a size of greater than $4 \mathrm{~cm}$.

In $62.5 \%$ of the patients, progression in the form of distant metastases occurred during the follow-up period. The median progression-free survival time was 6 months in our patient collective. These numbers correspond with published data and it must be taken into consideration that these are patients with advanced-stage cancer for whom a minor gain in time without tumor therapy and chemotherapy is of great importance.

Ricke and colleagues who first studied this procedure found similar results in earlier studies: In a prospective phase-III study with 73 patients, local tumor progression occurred in $25.1 \%$ of the patients [20].

The higher local progression rate in the study can be attributed to the fact that the study was a dose finding study for the treatment of colorectal liver metastases. Therefore, some of the patients were treated with a radiation dose that proved to be suboptimal for this tumor entity.

Based on the results of this study, we treated all suitable patients with a minimum tumor-enclosing dose of $20 \mathrm{~Gy}$. In our opinion this is the decisive reason for the higher local tumor control rate in our study.

Moreover, the average tumor size $(36 \mathrm{~mm})$ in the study by Ricke et al. was greater which was associated with a higher relapse rate even in the case of treatment with CT-HDRBT. In conclusion, in our study CT-HDRBT proved to be a suitable treatment method for the local ablation of unresectable liver metastases in colorectal tumors. Good results were achieved in small and large metastases. However, it was shown that the local relapse rate in metastases increases starting at a size of $4 \mathrm{~cm}$. Combination therapy with other local or systemic treatments should be examined in prospective studies. 


\section{Affiliations}

1 Department of Diagnostic and Interventional Radiology, Charité, Campus Virchow-Klinikum, Augustenburger Platz 1, 13353 Berlin, Germany

2 Department of Oncology, Charité, Campus Virchow-Klinikum, Augustenburger Platz 1, 13353 Berlin, Germany

3 Department of General, Visceral and Transplantation Surgery, Charité, Campus Virchow-Klinikum, Augustenburger Platz 1, 13353 Berlin, Germany

${ }^{4}$ Department of Radiation Oncology, Charité, Campus Virchow-Klinikum, Augustenburger Platz 1, 13353 Berlin, Germany

\section{References}

1 Robert Koch-Institut. (Hrsg) Sterblichkeit, Todesursachen und regionale Unterschiede. Gesundheitsberichterstattung des Bundes. Heft 52. Berlin: RKI; 2011

2 Nordlinger B, Sorbye H, Glimelius B et al. Perioperative chemotherapy with FOLFOX4 and surgery versus surgery alone for resectable liver metastases from colorectal cancer (EORTC Intergroup trial 40983): a randomised controlled trial. Lancet 2008; 22 (371): 1007-1016

3 Schindl M, Gruenberger Th, Längle F. Current strategies in the treatment of colorectal cancer liver metastases: aspects of surgical treatment. European Surgery 2008; 16: 332-336

4 Garden OJ, Rees M, Poston GJ et al. Guidelines for resection of colorectal cancer liver metastases. Gut 2006; 55: (Suppl 3): iii1 - iii8

5 Folprecht G, Gruenberger T, Bechstein WO et al. Tumour response and secondary resectability of colorectal liver metastases following neoadjuvant chemotherapy with cetuximab: the CELIM randomised phase 2 trial. Lancet Oncol 2010; 11: 38-47

6 Adam R, Wicherts DA, de Haas RJ et al. Patients with initially unresectable colorectal liver metastases: is there a possibility of cure? Journal of Clinical Oncology 2009; 27: 1829-1835

7 Solbiati L, Ierace T, Goldberg SN et al. Percutaneous US-guided radiofrequency tissue ablation of liver metastases: treatment and followup in 16 patients. Radiology 1997; 202: 195-203

8 Solbiati L, Livraghi T, Goldberg SN et al. Percutaneous radio-frequency ablation of hepatic metastases from colorectal cancer: long-term results in 117 patients. Radiology 2001; 221: 159-166

9 Livraghi T, Solbiati L, Meloni F et al. Percutaneous radiofrequency ablation of liver metastases in potential candidates for resection: the "testof-time approach". Cancer 2003; 15 (97): 3027-3035

10 Gillams AR, Lees WR. Radio-frequency ablation of colorectal liver metastases in 167 patients. European Radiolology 2004; 14: 2261 -2267

11 Jakobs TF, Hoffmann RT, Trumm $C$ et al. Radiofrequency ablation of colorectal liver metastases: mid-term results in 68 patients. Anticancer Res 2006; 26: 671-680

12 Sørensen SM, Mortensen FV, Nielsen DT. Radiofrequency ablation of colorectal liver metastases: long-term survival. Acta Radiol 2007; 48: $253-258$

13 Veltri A, Sacchetto P, Tosetti I et al. Radiofrequency ablation of colorectal liver metastases: small size favourably predicts technique effectiveness and survival. Cardiovascular Interventional Radiolology 2008; 31: $948-956$

14 Gillams AR, Lees WR. Five-year survival following radiofrequency ablation of small, solitary, hepatic colorectal metastases. Journal of Vascular and Interventional Radiology 2008; 19: $712-717$

15 Veltri A, Guarnieri T, Gazzera C et al. Long-term outcome of radiofrequency thermal ablation (RFA) of liver metastases from colorectal cancer (CRC): size as the leading prognostic factor for survival. Radiol Med 2012; 117: 1139-1151

16 Solbiati L, Ahmed M, Cova L et al. Small Liver Colorectal Metastases Treated with Percutaneous Radiofrequency Ablation: Local Response Rate and Long-term Survival with Up to 10-year Follow-up. Radiology 2012; 265: $958-968$
17 Ruers T, Punt C, Van Coevorden F et al. Radiofrequency ablation combined with systemic treatment versus systemic treatment alone in patients with non-resectable colorectal liver metastases: a randomized EORTC Intergroup phase II study (EORTC 40004). Ann Oncol 2012; 23: $2619-2626$

18 Mulier S, Ni Y, Jamart J et al. Local recurrence after hepatic radiofrequency coagulation: multivariate meta-analysis and review of contributing factors. Annals of Surgery 2005; 242: $158-171$

19 Ricke J, Wust P. Computed tomography-guided brachytherapy for liver cancer. Semin Radiat Oncol 2011; 21: 287-293

20 Ricke J, Mohnike K, Pech $M$ et al. Local response and impact on survival after local ablation of liver metastases from colorectal carcinoma by computed tomography-guided high-dose-rate brachytherapy. Int J Radiat Oncol Biol Phys 2010; 78: 479-485

21 Collettini F, Schnapauff D, Poellinger A et al. Hepatocellular carcinoma: computed-tomography-guided high-dose-rate brachytherapy (CTHDRBT) ablation of large $(5-7 \mathrm{~cm})$ and very large $(>7 \mathrm{~cm})$ tumours. Eur Radiol 2012; 22: 1101-1109

22 Ricke J, Thormann M, Ludewig $M$ et al. MR-guided liver tumor ablation employing open high-field 1.0 T MRI for image-guided brachytherapy. Eur Radiol 2010; 20: 1985-1993

23 Goldberg SN, Grassi CJ, Cardella JF. for the Society of Interventional Radiology Technology Assessment Committee and the International Working Group on Image-guided Tumor Ablation. . et al. Image-guided tumor ablation: standardization of terminology and reporting criteria. J Vasc Interv Radiol 2009; 20: S377-S390

$24 \mathrm{Lu}$ DS, Raman SS, Vodopich DJ et al. Effect of vessel size on creation of hepatic radiofrequency lesions in pigs: assessment of the "heat sink" effect. Am J Roentgenol Am J Roentgenol 2002; 178: 47-51

$25 \mathrm{Li}$ Y, Brown RE, Martin RC. Incomplete thermal ablation of hepatocellular carcinoma: effects on tumor proliferation. J Surg Res 2013; 181: $250-255$

26 Kennedy AS, Coldwell D, Nutting C et al. Resin 90Y-microsphere brachytherapy for unresectable colorectal liver metastases: modern USA experience. Int J Radiat Oncol Biol Phys 2006; 65: 412-425

27 Jakobs TF, Hoffmann RT, Dehm K et al. Hepatic yttrium-90 radioembolization of chemotherapy-refractory colorectal cancer liver metastases. J Vasc Interv Radiol 2008; 19: 1187-1195

$28 \operatorname{der}$ Pool AE, Méndez RomeroA, Wunderink W et al. Stereotactic body radiation therapy for colorectal liver metastases. Br J Surg 2010; 97: 377-382

29 Bae SH, Kim MS, Cho CK et al. High dose stereotactic body radiotherapy using three fractions for colorectal oligometastases. J Surg Oncol 2012; 106: $138-143$

30 Scorsetti M, Arcangeli S, Tozzi A et al. Is stereotactic body radiation therapy an attractive option for unresectable liver metastases? A preliminary report from a phase 2 trial. Int J Radiat Oncol Biol Phys 2013; 86: $336-342$

31 Berber B, Ibarra $R$, Snyder $L$ et al. Multicentre results of stereotactic body radiotherapy for secondary liver tumours. HPB 2013; DOI: 10.1111/hpb.12044

32 Mohnike K, Wieners G, Schwartz F et al. Computed tomography-guided high-dose-rate brachytherapy in hepatocellular carcinoma: safety, efficacy, and effect on survival. Int J Radiat Oncol Biol Phys 2010; 78: $172-179$

33 Wieners G, Mohnike K, Peters $N$ et al. Treatment of hepatic metastases of breast cancer with CT-guided interstitial brachytherapy - a phase IIstudy. Radiother Oncol 2011; 100: 314-319

34 Collettini $F$, Golenia M, Schnapauff $D$ et al. Percutaneous computed tomography-guided high-dose-rate brachytherapy ablation of breast cancer liver metastases: initial experience with 80 lesions. J Vasc Interv Radiol 2012; 23: 618-626 